\title{
Research on Evolution of Earthquake Disaster Social Risk Based on System Dynamics
}

\author{
Weiwei Zhang, Xuanhua Xu*, Xuanpeng Yin, Yanfen Yu \\ School of business, Central South University, Changsha 410083, China
}

\section{基于系统动力学的地震灾害社会风险演化研究}

张威威, 徐选华 ${ }^{*}$, 尹儇鹏, 余艳粉

中南大学商学院, 长沙 410083 , 中国

\begin{abstract}
In order to solve the problem of earthquake disaster emergency rescue and emergency resource allocation and the social risk change of earthquake disaster, based on the analysis of the interrelationships of various elements of earthquake hazard social risk evolution system, the method of system dynamics was used to construct the earthquake disaster The evolution of social risk, causal graph and system dynamics model, and the Nepal earthquake as an example, the evolution of the social risk of earthquake disaster simulation analysis. The simulation results show that the different allocation of emergency resources will have a certain impact on the social risk of earthquake disaster. The less the allocation of resources, the greater the possibility of the occurrence of social disasters, to provide a reference for how to reasonably allocate emergency resources for the emergency departments when conducting emergency risk management.
\end{abstract}

Keywords: earthquake; system dynamics; social risk; risk evolution

\section{摘要}

针对地震灾害应急救援过程中, 应急资 源配置与地震灾害社会风险变化的问题, 在

*通讯作者: xuxh@csu.edu.cn
深入分析地震灾害社会风险演化系统的各 要素相互关系的基础上, 采用系统动力学的 研究方法, 构建了地震灾害社会风险演化的 因果关系图和系统动力学模型, 并以为尼泊 尔地震为例, 对地震灾害社会风险演化进行 了仿真分析。仿真结果表明: 应急资源配置 的不同，会对地震灾害社会风险产生一定的 影响, 资源配置越少, 地震灾害社会风险发 生的可能性也就越大, 从而为应急部门在进 行应急风险管理时, 如何合理配置应急资源 提供参考依据。

关键词: 地震; 系统动力学; 社会风险; 风险演化

\section{1. 引言}

近年来我国重大突发事件的发生呈显 著上升趋势, 突发事件种类明显增多, 突发 事件发生频率明显增高, 涉及范围明显扩大, 突发事件及其影响的复杂性和应对难度显 著加大, 给国家经济和人民生命财产造成重 大损失，同时造成了严重的社会问题 [1-3]。 地震灾害作为重大突发事件的一种, 其发生 频繁, 破坏力极强, 波及范围广, 甚至可能 会产生一系列的社会风险问题, 这些问题如 果得不到及时有效的解决而被逐渐积累, 很 容易演化为群体性事件, 降低社会的稳定性 和安全性 [4]。而且地震灾害发生后, 对灾 区及时的救援是减轻灾民损失和痛苦的最 重要的措施, 如救援物资的调集、救援医疗 人员的分配数量、救援资金的数量以及救援 交通工具的安排等, 如果这些救援措施实施 
不当, 会导致灾民心理失衡、社会失序等社 会风险的发生, 甚至可能转化为社会危机。 因此, 如此合理调度应急救助资源, 探索地 震灾害社会风险的演化机理, 提出风险应对 建议, 是目前应急管理部门亟待解决的问题。

目前国内外学者对风险演化已作出一 些研究, 陈庭强等 [5]采用复杂网络的动力 学理论, 建立基于复杂网络的金融信用风险 演化模型, 并通过仿真研究探讨了金融信用 风险中监管者的监控强度、个体风险抵抗能 力等因素对金融信用风险演化的影响; 陈长 坤等 [6] 以莫拉克台风为例, 研究了台风灾 害演化系统风险问题, 构建了基于复杂网络 的台风网络演化模型, 并利用复杂网络节点 的出入度、子网节点数等理论确定台风风险 演化过程中的关键节点, 从而为台风治理提 供建议; Dunia 等 [7]针对决策过程中个体的 行为容易受到其他个体的决策影响这一现 象, 根据复杂网络原理构建个体决策行为演 化模型, 并通过平均场方法得到其演化的规 律; Xu 等 [8]分析了重特大洪涝灾害社会稳 定风险的演化过程, 利用复杂网络理论刻画 了洪涝灾害社会稳定风险演化的拓扑结构 图, 并利用改进的复杂网络理论中紧密度指 标, 对拓扑结构图中各个节点的出入度、节 点的距离进行分析计算, 确定社会稳定风险 演化过程中的关键节点, 为洪涝灾害管理提 供理论参考; 马祖军等 [9] 为了研究城市地 震次生灾害的演化规律, 构建了基于贝叶斯 网络的城市地震次生灾害演化模型, 并利用 贝叶斯网络工具箱得出各类城市地震次生 灾害的发生概率, 从而为城市防震工作提供 参考依据; 王勇胜等 [10]指出集群环境下群 风险的理论中, 缺少网络环境下的风险演化 研究, 并利用贝叶斯网络对项目群风险演化 进行了分析, 为项目群环境下的风险管理提 供建议; Zhang 等 [11]探讨了隧道施工中不 确定性的安全风险问题, 利用模糊贝叶斯网 络分析影响安全风险的各变量之间的因果 关系, 提出一种专家可信度指标来保证基本 风险因素概率的可靠性, 并用实证论证所提 出方法的可行性, 从而增加了项目在复杂环 境中成功的可能性; Goh 等 [12], 杨浩雄等 [13]研究了城市交通安全问题, 分析了造成
交通拥堵的原因, 影响等, 并建立基于系统 动力学的城市交通安全的系统动力学模型, 对解决城市交通拥堵的对策进行仿真分析, 为解决交通拥堵问题提供建议; Mariagrazia 等 [14]利用系统动力学模型研 究了旅行过程中由蚊子传播疾病的传染过 程, 分析了蚊子的生命周期和人类旅行中的 行为, 并通过对不同的疾病控制策略进行分 析比较, 得出不同时期不同行为下传染病控 制策略的不同组合。

综上可以看出, 风险演化的研究方法基 本上有复杂网络法、系统动力学方法、贝叶 斯网络法等, 风险演化的研究已有一些成果, 但很少对灾害引发的社会风险演化过程进 行研究。现有的灾害社会风险的研究都是基 于对灾害社会风险的识别、灾害社会的预警 分析、灾害社会风险的应对策略研究等, 很 少对灾害社会风险演化规律和机理进行研 究。基于上述问题, 本文采用系统动力学的 方法对地震灾害社会风险演化过程进行定 量化研究, 通过对地震灾害社会风险的各个 因子间的关系进行分析, 建立地震灾害社会 风险系统动力学演化模型, 并利用模拟仿真 的方法来探索地震灾害社会风险动态演化 过程及其特征, 为防震救灾工作提供理论依 据和建议。

\section{2. 地震灾害社会风险演化的系统动力学模}

\section{型}

系统动力学可以从系统本身入手, 分析 系统整体结构与系统内部各影响因素之间 的关系, 有利于明确地表达要解决的问题, 确定系统的边界, 通过构建因果回路图、存 量流量图、政策结构图等将复杂的系统关系 转变为一定的数学关系。该模型注重的是系 统结构及其动态行为的研究, 对参数数据精 度要求相对较低。对于地震灾害社会风险而 言, 其风险难易量化, 无法得到精确的数据。 利用系统动力学建立社会风险模型, 通过科 学的赋值方法对社会风险影响因素进行量 化, 有效进行社会风险控制与管理。地震灾 害社会风险系统包括财产损失风险、社会失 序风险、社会稳定风险和心理失衡风险 4 个 子系统, 各子系统之间并非孤立存在, 单个 社会风险因素的发生可能会导致其他社会 
风险的发生、扩散进而导致整体系统的不稳 定, 甚至崩溃。依据系统动力学原理和地震

\section{1 系统边界的确定}

系统的边界是指研究问题中系统变量 的要素。重大地震灾害的发生不仅会给人类 的生命安全, 而且地震灾害的发生会严重破 坏人们的生存环境, 受灾主体在面对大的灾 难时, 他们的心理会受到严重的影响, 并且 形成了特殊的利益需求, 包括物资, 资金, 医疗服务, 交通工具等, 但是随着灾害造成 伤亡人数越来越多, 供水、食物、交通工具 等基本生活条件的需求越来越多, 同时他们 的需求得不到满足, 受灾主体就可能为了自 身的生存需要而引发社会冲突, 造成社会秩 序混乱, 人们往往会将这种结果的主要责任 归因于政府部门的救灾不力。如 2010 年 1 月 12 日海地地震, 由于救灾物资的不足, 灾民强抢救灾粮食等物资, 造成严重的社会 失序; 2015 年 4 月 29 日, 尼泊尔发生 8.1 级地震, 地震幸存者由于无法找到离开加德 满都的公交而引起民愤, 从而示威抗议政府 救灾不力。因此本文从救灾物资、救灾交通 工具、救灾医疗服务和救助资金四个方面入 手, 分析地震灾害社会风险的演化过程。

\section{2 地震灾害社会风险因果关系图}

在确定系统研究边界后, 经过对边界要 素之间关系的分析, 可以得到系统因果关系 图。因果关系图是对系统各变量间的相互关 系进行剖析, 是对系统内部结构关系的定性 描述。地震灾害社会风险是由客观因素和主 观因素的双重作用下发生的, 本文从以下几 个方面考虑地震灾害社会风险。

（1）财产损失风险。地震灾害本身, 地震灾害以及次生灾害造成的环境破坏, 直 接会引发财产损失风险的发生。地震的发生 会对周围环境造成严重的破坏, 如房屋倒塌、 农田损坏、牲畜死亡等, 这些实物财产会遭 受巨大的损失。如果在救援过程中, 灾民得 不到足够的救助资金, 无法弥补灾民所遭受 的部分财产损失, 就可能引发灾民的财产损 失风险。

（2）社会失序风险。地震灾害发生打
灾害社会风险因素之间的演化关系, 建立地 震灾害社会风险系统动力学模型。

破了社会原有正常运行的秩序, 造成人们生 活资料的结构性短缺, 失去生存所需的必要 的物质条件。在生存的压力下, 人们可能会 不顾法律和道德的约束, 发生非常规行为, 如抢劫财务、哄抢物资、暴力冲突等, 这些 都可能成为地震灾害带来的潜在社会风险。 如 2010 年 1 月发生的海地地震, 由于救援 物资的严重缺乏, 灾民无视警察的存在, 强 抢粮食等物资, 造成了严重的社会失序风险。

（3）社会稳定风险。地震灾害发生后, 灾区的交通会被切断, 当救援交通工具无法 满足救援需求时, 会造成大量的灾民滞后, 当他们求助无门时, 灾民会对政府缓慢的救 援措施感到失望, 当地的治安管理可能会无 法维持, 甚至可能导致较大的社会动荡, 严 重影响了社会的稳定性。

（4）心理失衡风险。重大地震灾害的 巨大破坏性不仅表现在物质方面的损失, 更 重要的是它能给灾民的心理造成强烈的影 响, 当灾害过后, 强烈的心理惊吓会刺激着 灾民, 使其处于一种非正常的心理状态, 这 种心理状态主要表现为焦虑、恐惧、情绪低 落等, 甚至会失落、绝望。这种心理如果不 及时治疗, 容易产生灾后综合症, 造成心理 失衡风险。

地震灾害社会风险的诱发因素, 包括救 灾物资、救灾交通工具、救灾医疗服务和救 助资金。其中, 救灾物资的缺乏会引发灾民 哄抢救灾物资, 导致社会失序风险的发生; 救灾交通工具的缺少, 容易造成大量灾民滞 留, 导致社会稳定风险的发生; 救灾医疗服 务的不完善, 容易给灾民的心理带来创伤, 造成心理失衡风险的发生; 救助资金的不足, 给灾民带来财产损失, 导致财产损失风险的 发生。根据救灾物资、救灾交通工具、救灾 医疗服务和救助资金四个子系统内部各变 量的相互关系, 画出地震灾害社会风险的因 果关系图, 如下图 1 所示。图中箭头表示变 量之间的因果关系, 正号和负号分别表示正 效应和负效应。 


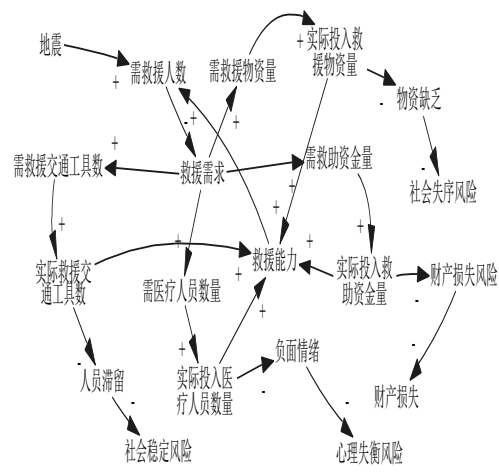

图 1 地震灾害社会风险因果关

\section{3 地震灾害社会风险系统模型的建立}

在因果关系图确定之后, 用系统动力学 软件 Vensim 建立地震灾害社会风险演化的 系统动力学模型, 模型如图 2 所示。

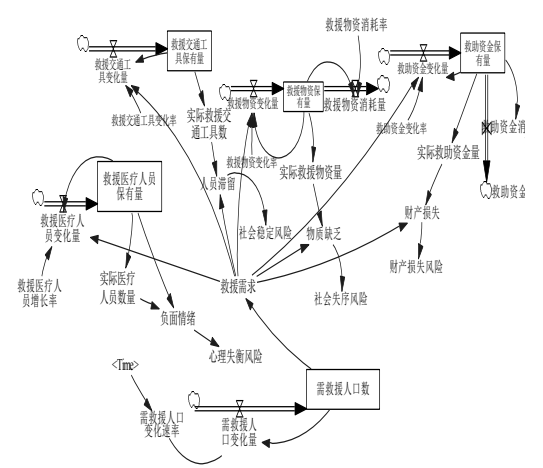

图 2 地震灾害社会风险演化系统动力学模 型

\section{4 系统模型参数设置}

在对系统动力学模型进行仿真运行之 前, 需要对模型中的各种参数进行赋值、模 型中各个变量的方程进行确定。

本文借鉴孙漟悦等[15]、汪建等[16]的研 究成果, 并查阅尼泊尔地震相关数据资料, 给出模型变量的参数, 如下所示:

(1) 需救援人口数=INTEG（需救援人口变 化量, 22303)

(2) 救援医疗人员保有量 $=$ INTEG（救援医 疗人员变化量, 1500）

（3）救援交通工具保有量=INTEG（救援交
通工具变化量, 1000)

（4）救援物资保有量 $=$ INTEG（救援物资变 化量一救援物资消耗量, 100)

（5）救助资金保有量=INTEG（救助资金变 化量一救助资金消耗量, 3000)

（6）负面情绪=IF THEN ELSE（实际医疗 人员数量 $>$ 救援医疗人员保有量, 0 , 救援 医疗人员保有量 - 实际医疗人员数量)

(7) 人员滞留 $=$ IF THEN ELSE (实际救援 交通工具数 $* 20>$ 救援需求, 0 , 救援需求 -20 *实际救援交通工具数)

（8）财产损失 $=$ IF THEN ELSE（实际救助 资金量-救援需求 $* 15>0,0$, 救援需求 $* 15$-实 际救助资金量）

（9）物资缺乏 $=$ IF THEN ELSE（实际救援 物资量-救援需求 $>0,0$, 救援需求-实际救援 物资量)

\section{3 地震灾害社会风险演化系统动力学模型 检验}

\section{1 模型的稳定性检验}

为了验证模型的稳定性, 选取不同的时 间仿真步长 DT 进行仿真分析, 分别对 DT $=1$ 、 $\mathrm{DT}=0.5$ 进行仿真, 检验状态变量的变化趋势, 如图 3 所示, 其中 current 表示 $\mathrm{DT}=1$ 时状态 变量变化情况, current 1 表示 DT $=0.5$ 时状态 变量变化情况。

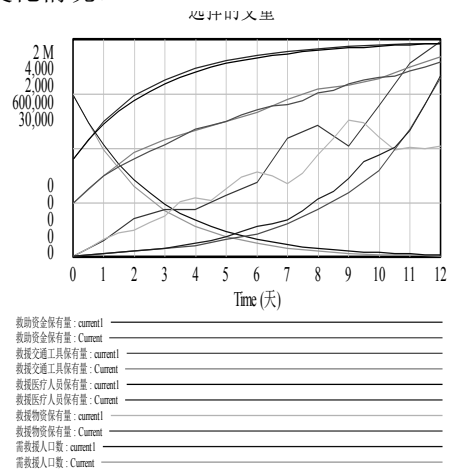

图 3 状态变量对时间步长 (1 到 0.5) 的变 化灵敏图

从图 3 可以看出, 当步长从 0.5 变到 1 的时候, 各个状态变量的变化情况基本一致, 状态变量的上升和下降趋势基本同步, 由此 说明模型的稳定性较好。 


\section{2 模型的仿真结果检验}

为了验证模型的仿真结果的有效性, 本 文选取 2015 年 4 月 25 日尼泊尔地震案例, 对该模型进行验证。此次地震震级为 8.1 级, 总共造成 22303 人受伤, 将此数据作为本文 中的初始参数, 对尼泊尔地震社会风险进行 系统动力学仿真模拟。

由于在实际的救援过程中, 需要多种救 援交通工具、多种类型的救援物资以及多种 类型的救援医疗人员, 考虑到相关数据不易 获取, 因此本文并没有进行细分。模型中仿 真模拟时间为 12 天, 时间间隔为 1 天。

为了定量描述地震灾害社会风险, 本文 引入聂高众等 [17] 提出的地震应急救援需 求的概念模型, 其表述为:

$$
\mathrm{Y}=K_{x} Q_{x} F_{x}-\delta C_{y}
$$

其中, $Y$ 表示某种救灾物资或者救灾人员的 实际最小需求量; $K_{x}$ 表示受灾区的地区系数; $Q_{x}$ 表示气候系数, $F_{x}$ 表示某种救灾物资或者 救灾人员的理论统计需求量, $F_{x}$ 根据灾区总 人口、地震伤亡人数、房屋倒塌等地震实际 情况计算出来的, 且 $F_{x}=f(\alpha$, 死伤人数 $)+$ $f(\beta$, 灾区总人口 $)+f(\gamma$, 无家可归人数 $)+$ $f(\theta$, 其他 $), \alpha, \beta, \gamma, \theta$ 为需求系数; $C_{y}$ 表示受 灾地区该类救灾物资或者救灾人员的现有 数; $\delta$ 为灾后保全率。

文中的地震灾害救援需求的相关系数 $(\alpha, \beta, \gamma, \theta)$ 和系统中的计算公式如下:

需救援交通工具数 $=$ 地区系数 $*(0.06 *$ 受伤 人数 $+0.004 *$ 灾区总人口)

需医疗人员数 $=$ 地区系数 $* 0.11 *$ 受伤人数 需救援物资量=地区系数* ( $5.7 *$ 受伤人数 $+1.6 *$ 灾区总人口)

需救助资金数 $=100 *$ 受伤人数 $+25 *$ 灾区总人 口

通过上述公式以及仿真结果, 得出模型 的仿真结果检验表, 如表 1 所示。

由表 1 可以看出, 对比计算值, 模型的 各个预测值的相对误差均在 $5 \%$ 以内, 因此 可以说明该模型是真实有效的 [18-19], 可以 利用该模型对地震灾害社会风险演化状况 进行分析和预测。
表 1 模型仿真结果检验

\begin{tabular}{|c|c|c|c|c|}
\hline $\begin{array}{l}\text { 参 } \\
\text { 数 }\end{array}$ & $\begin{array}{c}\text { 救援医 } \\
\text { 疗人员 } \\
\text { 保有量 } \\
\text { (人) }\end{array}$ & $\begin{array}{c}\text { 救援交 } \\
\text { 通工具 } \\
\text { 保有量 } \\
\text { (辆) }\end{array}$ & $\begin{array}{l}\text { 救援物 } \\
\text { 资保有 } \\
\text { 量（件） }\end{array}$ & $\begin{array}{l}\text { 救助基 } \\
\text { 金保有 } \\
\text { 量（万 } \\
\text { 元） }\end{array}$ \\
\hline $\begin{array}{l}\text { 计 } \\
\text { 算 } \\
\text { 值 }\end{array}$ & 2713 & 3837 & 614457 & 17294 \\
\hline $\begin{array}{l}\text { 模 } \\
\text { 拟 } \\
\text { 值 }\end{array}$ & 2585 & 3668 & 593151 & 16436 \\
\hline $\begin{array}{l}\text { 误 } \\
\text { 差 }\end{array}$ & 4. $7 \%$ & $4.4 \%$ & $3.5 \%$ & $5.0 \%$ \\
\hline
\end{tabular}

\section{4. 模拟仿真与结果分析}

\section{1 需救援人口数分析}

周阿颖等 [20]研究表明, 地震发生后的 救灾速率存在明显的时空特征, 最开始的时 间救灾速率变化比较大, 随着时间的推移救 灾速率越来越小, 最后趋近于饱和, 并且救 灾速率变化最快的时间段大体上为灾后发 生的 10 小时至 75 小时。这些结果表明, 灾 后救援的最佳时间为灾后发生的前三天, 此 时应急救援效果最佳, 超过这个时间, 灾后 救援的效率会逐渐降低。从图 4 需救援人口 模拟图可以看出, 地震发生后的前三天由于 救援效率比较高, 获得营救的灾民会较多, 而剩下的需救援人口就会越来越少。 而数抜八山数

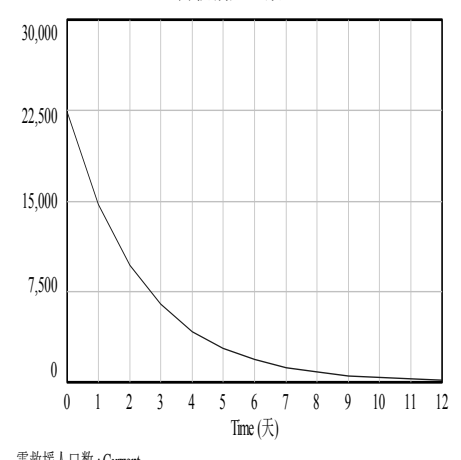

需救援人口数: Current

图 4 地震灾害需救援人口数变化情况

\section{2 救援医疗人员量与心理失衡风险分析}

地震灾害破坏力巨大, 影响范围广, 严 
重威胁到人们的生命安全。地震灾害发生后, 当地医疗部门需要结合实际情况, 迅速组建 地震灾害紧急救援医疗队。地震发生后, 由 于灾区的道路、医疗卫生站等遭到破坏, 各 地的救援队伍很难在短时间内迅速聚集, 因 此在灾害发生之处灾区实际的救援医疗人 员较少, 大多的灾民得不到基本的医疗救治, 地震灾害容易给灾民带来强烈的惊吓, 他们 的心理状态已经处于临界状态, 再加上得不 到基本的医疗救治的刺激, 诱发灾民产生强 烈的消极情绪, 引发心理失衡风险。随着救 援医疗人员的不断增多, 越来越多的灾民得 到救治, 他们的消极情绪得到安慰, 从而减 少了地震灾害给灾民造成的心理伤害。

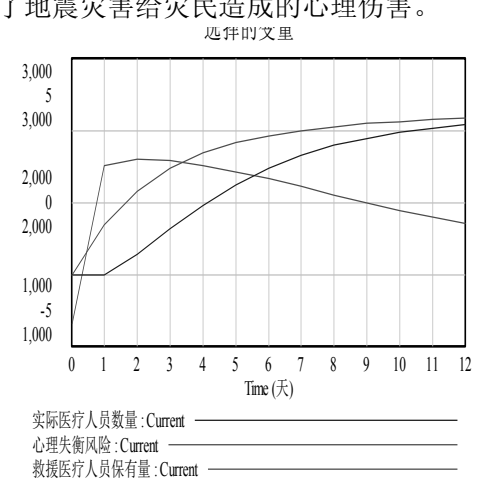

图 5 地震灾害救援医疗人员数量和心理失 衡风险变化情况

\section{3 救援物资量与社会失序风险分析}

地震发生后, 不同的震级、地区, 所需 要的救援物资的种类和数量是不同的。本文 由于获取数据有限, 故未细分救援物资种类。 地震发生初期, 灾区的通讯等受到破坏, 紧 急救援部门很难第一时间获得较为准确的 受灾人数, 并且道路等受到破坏, 救援物资 很难及时输送到灾区, 救援物资的增加速率 较为缓慢。随着救援工作的逐步进行, 越来 越多的灾民得到救助, 所需要的救援物资数 量增加趋势也越来越显著。但是在地震初期 对救援物资的调集数量不够, 物资极其短缺, 大量的灾民无法获取基本的生活必需品, 为 了生存他们可能会做出一些非理智的行为, 如哄抢食物, 群体性暴力冲突等, 从而促进 了地震灾害社会失序风险的发生。

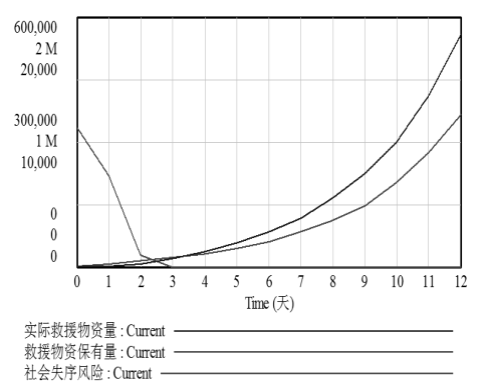

图 6 地震灾害救援物资量与社会失序风险 变化情况

\section{4 救援交通工具量与社会稳定风险分析}

由上图 6 可以看出, 救援物资的保有量 在逐渐增多, 救援交通工具的数量也基本与 救援物资的变化趋势一致。地震灾害初期, 灾区的应急救援管理部门会配备一定的救 援车辆, 但是地震灾区较大, 无法满足救援 需求, 从而造成较多的灾民滞留在灾区。地 震的突然袭击, 使得人们的基本生存物质和 精神瞬间崩塌, 加上不断的余震发生, 人们 有迫切的想法离开灾区, 救援车辆的不足可 能会引发地震灾害埋下的社会失序风险。如 尼泊尔发生 8.1 级地震, 由于救灾初期救援 交通工具的调集数量明显不足, 尼泊尔首都 加德满都的灾民由于无法找到离开的公交 而引起民愤, 从而示威抗议政府救灾不力, 打破了原有的社会稳定的状态。随着救援的 不断推进, 救援交通工具的不断增多, 越来 越多的灾民得到安置, 灾民心里恐惧的情绪 得到减缓, 降低了地震灾害社会稳定风险的 发生。

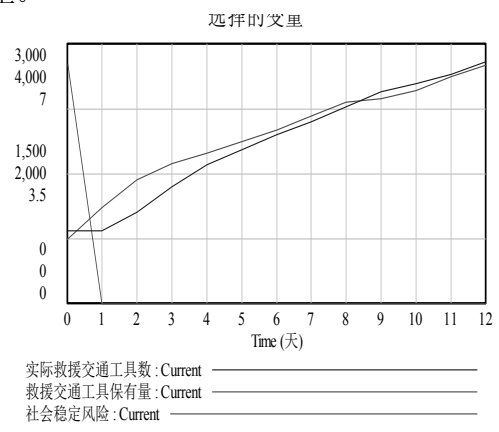

图 7 地震灾害救援交通工具量与社会稳定 风险变化情况 


\section{5 救助资金量与财产损失风险分析}

地震灾害发生后，灾民需要大量的资金 需求，其中主要包括应急救灾款、灾民医疗 费用、搬迁费用、灾民生活费用等。随着上 述救灾工作的开展, 救助资金的数量呈不断 上升的趋势。地震灾害发生初期, 灾民的实 物财产如房屋、田地等遭到破坏，给灾民造 成了巨大的财产损失。救灾之初, 应急部门 短时间无法积聚巨大的资金, 实际投入的救 助资金量远远小于所需要的救助资金量, 无 法弥补灾民巨大的财产损失, 增加了财产损 失风险。而随着各国政府的支持以及社会各 界团体的援助, 救助资金不断增多, 灾民的 财产损失得到补偿, 从而降低了财产损失风 险的发生。

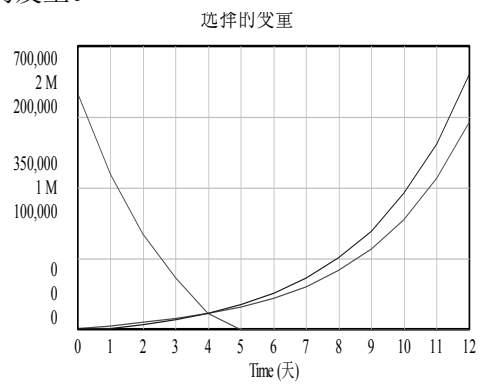

$$
\text { 实际救助资金量 : Current }
$$
救助资金保有量: Current
财产损失风险: Current

图 8 地震灾害救助资金量与财产损失风险 变化情况

\section{6 讨论}

本文从地震灾害应急救援角度出发, 对 地震灾害救援过程中的救援物资、救援交通 工具、救援医疗人员、救助资金配备问题进 行讨论, 通过分析各个应急救援资源的数量 变化, 探讨相应的地震灾害社会风险变化情 况, 从而为降低地震灾害社会风险的。文中 没有细分各个救灾资源的种类, 只是粗略的 将这些资源集中考虑。灾区的不同、受灾程 度的不同, 所需要的救灾资源是不相同的, 细分灾民对救援资源的不同需求, 考虑多种 救灾资源对地震灾害应急救援的影响, 理清 应急救援水平对地震灾害社会风险的影响 是今后的研究方向。其次, 本文仅仅粗略地
探讨了应急资源的不同配置与相应的地震 灾害社会风险变化情况。但是, 不同类型的 应急资源与相应社会风险发生的比例关系, 难以找到准确的平衡点, 这也值得今后深入 研究。

\section{5. 结论}

针对地震灾害救援过程中应急资源配 置与灾害社会风险变化的问题, 本文结合研 究区域实际情况建立地震灾害社会风险演 化的系统动力学模型, 对不同的应急资源进 行仿真模拟, 实现了地震应急救援过程中救 援医疗人员、救援物资、救援交通工具、救 助资金等的动态模拟, 从模拟结果中可以看 出在应急救援过程中应急资源投入的数量, 会对灾害社会风险产生一定的影响。因此, 应急救援部门应合理配置应急资源, 加大应 急资源的投入, 并重视灾害对灾民心理健康 的影响, 从而降低社会风险水平。但是, 由 于获取数据的有限, 部分变量的设定具有较 强的主观性, 在一定程度上降低了模拟结果 的准确性, 因此后续研究应提高模型的准确 性。

\section{Acknowledgements}

This study was supported by National Social Science Foundation of China (No.71671189), Central South University Postgraduate Independent Exploration and Innovation Project(No. 502211804).

\section{致谢}

本研究得到了国家自然科学基金项目 (71671189) 和中南大学研究生自主探索创 新项目（502211804）的资助。

\section{参考文献}

[1] 吴绍洪, 靳京, 郑景云. 中国地震灾害中 “伤亡比”指标的估算. 地理科学进展, 2015, 34(7): 918-925.

[2] 徐锡蒙, 郑粉莉, 关颖慧, 等. 2013 年我国 地震灾害时空特征与灾害损失分析. 水 土保持研究, 2015, 22(4): 321-325.

[3] 王曦, 周洪建. 区域地震灾害年度风险 
评估中的情景分析. 灾害学, 2015(2): 70-74.

[4] Cheng J W, Mitomo H, Otsuka T, et al. The effects of ICT and mass media in post-disaster recovery - A two model case study of the Great East Japan Earthquake. Telecommunications Policy, 2015, 39(6):515-532.

[5] 陈庭强, 何建敏. 基于复杂网络的信用 风险传染模型研究. 中国管理科学, 2014, 28(11):111-117.

[6]陈长坤, 纪道溪. 基于复杂网络的台风灾 害演化系统风险分析与控制研究. 灾害 学, 2012, 27(1):1-4.

[7]López-Pintado D. Diffusion in complex social networks. Games \& Economic Behavior, 2008, 62(2):573-590.

[8] Xu X H, Wang C H, Cai C G, et al. Evolution and coping research for flood disaster social stability risk based on the complex network. Natural Hazards, 2015, 77(3):1491-1500.

[9] 马祖军, 谢自莉. 基于贝叶斯网络的城 市地震次生灾害演化机理分析. 灾害学, 2012, 27(4):1-5.

[10] 王勇胜, 冷亚军. 基于贝叶斯网络推理 的项目群风险及其演化研究. 东北电力 大学学报, 2011, 31(6):104-109.

[11] Zhang L, Wu X, Skibniewski M J, et al. Bayesian-network-based safety risk analysis in construction projects. Reliability Engineering \& System Safety, 2014, 131(3):29-39.

[12] Goh Y M, Love P. Methodological application of system dynamics for evaluating traffic safety policy. Safety Science, 2012, 50(7):1594-1605.

[13] 杨浩雄, 李金丹, 张浩,等. 基于系统动 力学的城市交通拥堵治理问题研究系 统工程理论与实践, 2014, 34(8):2135-2143.

[14] Mecoli M, Angelis V D, Brailsford S C, et al. Using system dynamics to evaluate control strategies for mosquito-borne diseases spread by human travel. Computers \& Operations Research, 2013, 40(9):2219-2228.

[15] 孙㳥悦, 杨青山, 陈鹏, 等. 草原牧区 雪灾应急救助需求系统动力学模型与 实证研究. 干旱区资源与环境, 2016, 30(6): 108-114.

[16] 汪建, 赵来军, 顾彩云. 地震应急避难 需求的系统动力学研究. 中国安全科学 学报, 2013, 23(1): 121-128.

[17] 聂高众, 高建国, 苏桂武, 等. 地震应急 救助需求的模型化处理一一来自地震 震例的经验分析. 资源科学, 2001, 23(1):69-76.

[18] Fu Y, Piplani R. Supply-side collaboration and its value in supply chains. European Journal of Operational Research, 2004, 152(1):281-288.

[19] Lin J, Linb $T$ E. Object-oriented conceptual modeling for commitment-based collaboration management in virtual enterprises. Information \& Software Technology, 2004, 46(4):209-217.

[20] 周阿颖, 张朝, 史培军, 等. 影响地震救 灾效率的因素分析一以汶川 8.0 级地 震和玉树 7.1 级地震为例. 灾害学, 2011, 26(4):134-138. 